\title{
ANATOMIA DA MADEIRA DE TRÊS ESPÉCIES BRASILEIRAS DE BACCHARIS L. (ASTERACEAE - ASTEREAE) ${ }^{1}$
}

\author{
JOSÉNEWTONCARDOSOMARCHIORI ${ }^{2}$ ANABELASILVEIRADEOLIVEIRA ${ }^{3}$
}

\section{RESUMO}

São anatomicamente descritas as madeiras de Baccharis dracunculifolia DC., B. patens Baker e B. tridentata Vahl. As três espécies reúnem as seguintes características: porosidade difusa; vasos numerosos, de pequeno diâmetro; elementos vasculares com placas de perfuração simples e espessamentos espiralados; pontoações intervasculares alternas, diminutas a pequenas; pontoações raio-vasculares similares; parênquima paratraqueal; e fibras não septadas, com pontoações simples. O arranjo de poros é nitidamente dendrítico em Baccharis dracunculifolia e B. patens, espécies que também apresentam cristais em raios. Baccharis patens distinguese pelos raios compostos inteiramente de células quadradas.

Palavras-chave: Baccharis dracunculifolia, Baccharis patens, Baccharis tridentata, Anatomia da Madeira.

\section{ABSTRACT}

[Wood anatomy of three brazilian species of Baccharis L. (Asteraceae - Astereae)].

The woods of Baccharis dracunculifolia DC., B. patens Baker and B. tridentata Vahl are anatomically described. The three species show the following features: diffuse-porous; small and numerous vessels; vessel elements with simple perforation plates, helical thickenings and minute to small alternate intervessel pits; ray-vessel pits similar; paratracheal axial parenchyma; and non-septate fibres, with simple pits. The vessel arrangement is dendritic in Baccharis dracunculifolia and B. patens, species that also show prismatic chrystals in ray cells. Baccharis patens distinguishes itself by having only square cells in rays.

Key Words: Baccharis dracunculifolia, Baccharis patens, Baccharis tridentata, Wood Anatomy.

\section{INTRODUÇÃO}

Segunda família mais numerosa das Magnoliophyta, as Asteraceae (ou Compositae) compreendem 1.535 gêneros e mais de 23.000 espécies (Bremer, 1994), distribuídas nas regiões tropicais, subtropicais e temperadas do mundo. No Brasil, estão representados cerca de 180 gêneros, de acordo com Barroso (1991).

Com distribuição predominantemente extratropical, a tribo Astereae Cassini reúne 3.020 espécies, subordinadas a 14 subtribos e
192 gêneros (Nesom, 2000). Integrante dessa tribo botânica, o gênero Baccharis L. abrange cerca de 400 espécies de ervas perenes, subarbustos, arbustos e pequenas árvores, distribuídas desde o sul dos Estados Unidos até a Terra do Fogo (Giuliano, 2000).

Em estudo recente, Oliveira et al. (2006) reconheceram a existência de 146 espécies de Baccharis na flora brasileira. Algumas destas chegam a impor-se na fisionomia dos campos naturais do Rio Grande do Sul, compondo, jun-

1 Recebido em 10/01/2007 e aceito para publicação em 02/2/2007, o presente trabalho é resultado parcial de projeto contemplado com Bolsa de Produtividade em Pesquisa - CNPq. Os autores agradecem a Marcos Roberto Ferreira, acadêmico do curso de Engenharia Florestal da UFSM, pela colaboração nas medições anatômicas.

2 Engenheiro Florestal, Dr., bolsista de Produtividade em Pesquisa do CNPq, Professor Titular do Departamento de Ciências Florestais, Universidade Federal de Santa Maria, CEP 97105-900, Santa Maria (RS). balduinia@mail.ufsm.br

3 Bióloga, MSc., bolsista CAPES, doutoranda do Programa de Pós-Graduação em Engenharia Florestal, Centro de Ciências Rurais, Universidade Federal de Santa Maria, CEP 97105-900, Santa Maria (RS). anabela.biol@mail.ufsm.br 
tamente com outras Asteraceae, os chamados "vassourais". Vistas como importantes na apicultura, as espécies de Baccharis são também valorizadas como plantas medicinais, havendo sobre o gênero numerosas publicações sob os enfoques da fitoquímica e farmacognosia (Bonzanida Silva \& Grotta, 1971; Castro \& Ferreira, 2000; Jakupovic et al., 1990; Loyaza et al., 1995; Suttisri et al., 1994; Verdi et al., 2005).

O presente estudo, que dá início a uma série de publicações sobre a anatomia da madeira no gênero Baccharis, visa a descrição de três espécies nativas no Rio Grande do Sul: $B$. dracunculifolia DC., B. patens Baker e B. tridentata Vahl.

Arbusto de 2 a $3 \mathrm{~m}$ de altura, Baccharis dracunculifolia distribui-se da Bolívia e Paraguai até o sul do Brasil e Uruguai, sendo uma das espécies pioneiras antrópicas mais características em capoeiras e margem de estradas. As folhas, de 1-2,5 cm de comprimento por 3-4 mm de largura, são lanceoladas, papiráceas, uninérvias, densamente pontuadas de glândulas e com margens inteiras ou 1-3 dentes (Barroso, 1976).

Restrito ao Uruguai e Rio Grande do Sul, Baccharis patens Baker é arbusto de 05-1,5 m de altura, com ramos tomentosos e ramos da inflorescência patentes; as folhas, sésseis, uninérvias e de 1-2 cm de comprimento por 1-4 $\mathrm{mm}$ de largura, são tomentosas no dorso, estreitando-se gradativamente em direção ao ápice.

Arbusto xilopodífero de 0,5-1 m de altura, Baccharis tridentata Vahl apresenta ampla distribuição no sul do Brasil, Paraguai, Uruguai e centro-norte da Argentina. As folhas, com 1,5$5 \mathrm{~cm}$ de comprimento e $0,5-3 \mathrm{~cm}$ de largura, são sésseis, trinérvias, de ápice agudo ou arredondado, base longamente atenuada e 3-5 dentes em cada lado da margem (Barroso, 1976).

\section{REVISÃO DE LITERATURA}

A maior parte dos estudos anatômicos no gênero Baccharis L. foi desenvolvido com espécies de interesse medicinal: é o caso do tra- balho de Marinho (1996), sobre os órgãos vegetativos de Baccharis pseudotenuifolia Teodoro e B. dracunculifolia DC.; de Cortadi et al. (1999), dedicado especialmente às "carquejas" (Baccharis articulata, B. crispa, B. trimera); de Pereira \& Oliveira (1996), sobre a estrutura caulinar de Baccharis cylindrica; e de três publicações de Budel et al. (2003, 2004a, 2004b), que tratam da morfologia dos caules de Baccharis gaudichaudiana, B. cylindrica e $B$. dracunculifolia, respectivamente. Do material em estudo, apenas Baccharis dracunculifolia foi objeto de publicação e, mesmo assim, com enfoque distinto do buscado na presente pesquisa.

Apesar da abundância de espécies lenhosas na tribo Astereae e gênero Baccharis L., chama atenção a pobreza da literatura anatômica sobre suas madeiras, fato que pode ser atribuído ao escasso valor econômico das mesmas.

Em diagnose concisa, Record \& Hess (1949) relacionam aspectos anatômicos gerais para as Compositae (Asteraceae), sem fazer referências a detalhes estruturais em Baccharis L. Entre outros, são elencados para a família os seguintes aspectos do xilema secundário: porosidade difusa, menos comumente em anel; poros geralmente pequenos a diminutos, ocasionalmente de diâmetro médio; poros pouco freqüentes e solitários ou então numerosos, em múltiplos radiais ou em arranjos dendrítico e ulmiforme; elementos vasculares curtos, com placas de perfuração simples (raro escalariformes) e espessamentos espiralados (principalmente em espécies de regiões temperadas); pontoações intervasculares alternas, muito pequenas até grandes; raios homogêneos ou heterogêneos, com 3 ou mais, por vezes até 8-10 células de largura; parênquima paratraqueal escasso; e fibras geralmente septadas, com pontoações simples muito pequenas. Os autores referem a presença de estratificação em poucas espécies e de floema incluso em Artemisia tridentata Nutt., frisando, para o conjunto da família, a ausência de dutos gomíferos e de séries cristalíferas nos parênquimas axial e radial. 
A minuciosa descrição das Compositae, apresentada por Metcalfe \& Chalk (1972), relaciona para algumas espécies de Baccharis: vasos muito pequenos $(<50 \mu \mathrm{m})$, em padrão nitidamente radial e arranjo oblíquo ou em linhas tangenciais; porosidade em anel ou semidifusa; elementos vasculares com espessamentos espiralados em espécies de regiões temperadas; e parênquima axial com numerosas células fusiformes, por vezes estratificado. Os autores assinalam a presença de cristais solitários no parênquima axial de Ericameria, bem como nos raios de Ericameria e Proustia, diferentemente do reportado por Record \& Hess (1949). Sobre este último aspecto, Carlquist (1966) confirma a presença de cristais prismáticos em raras Compositae, incluindo, neste caso, o gênero Baccharis.

Para a tribo Asterae, Carlquist (1960) informa que o diâmetro médio dos poros, embora inferior a $50 \mu \mathrm{m}$ na maioria das espécies, pode ultrapassar de $100 \mu \mathrm{m}$, inclusive em alguns Baccharis (B. cassiniaefolia, B. concava, B. neglecta, $B$. thesioides). Com relação ao comprimento de elementos vasculares, o mesmo autor destaca que o caráter, inferior a $150 \mu \mathrm{m}$ na maioria das espécies, em poucos casos ultrapassa $300 \mu \mathrm{m}$, fato que pode ser atribuído tanto a uma posição filética mais elevada da tribo, dentro das Compositae, como à especialização acelerada, vinculada a habitats mais áridos. A presença de traqueídeos vasculares, igualmente relacionada à redução no diâmetro de vasos, foi referida para nove espécies: Baccharis angustifolia, B. glomerulifolia, B. halimifolia, B. lanceolata, B. obtusifolia, B. patagonica, B. rosmarinifolia, $B$. sergiloides e $B$. thesioides (Carlquist, 1960).

A respeito de espessamentos espiralados, Carlquist (1960) observou que o caráter pode ou não ocorrer no gênero em estudo. Por sua vez, a ausência de placas de perfuração escalariforme nas Astereae, com a única exceção de Grindelia cuneifolia, depõe favoravelmente a um alto grau de especialização do xilema, na tribo.
$\mathrm{O}$ arranjo ou agrupamento de vasos proporciona notável diversidade de padrões nas Astereae. Em Baccharis thesioides e $B$. viminea, por exemplo, o número de vasos por grupo é menor no lenho inicial, diferentemente do lenho tardio, onde os vasos, que são menores, compõem agrupamentos extremamente numerosos; nas demais espécies, os grandes agrupamentos estão distribuídos por todo o xilema. Vasos em racemos são reportados para Baccharis angustifolia e agregados tangenciais para B. rosmarinifolia. Grandes agregados de vasos, por sua vez, com freqüência reúnem-se em zig-zag ou arranjo diagonal, tanto em espécies de Baccharis como de Olearia.

\section{MATERIAL E MÉTODOS}

O material estudado, composto de amostras de madeira e respectivo material botânico, é procedente do Estado do Rio Grande do Sul e foi incorporado ao Herbário do Departamento de Ciências Florestais, da Universidade Federal de Santa Maria (HDCF), com os seguintes registros:

- Marchiori 842, 06.VIII.1987, Baccharis dracunculifolia, Hulha Negra, RS; HDCF 3224.

- Marchiori 841, 05.VIII.1987, Baccharis patens, Hulha Negra, RS; HDCF 3223.

- Marchiori 836, 06.VIII.1987, Baccharis tridentata, Canguçu, RS; HDCF 3218.

De cada uma das amostras de madeira foram preparados três corpos-de-prova, orientados para a obtenção de cortes anatômicos nos planos transversal, longitudinal radial e longitudinal tangencial. Os corpos-de-prova foram amolecidos por fervura em água e trabalhados em micrótomo de deslize, regulado para a obtenção de cortes anatômicos com espessura nominal de $20 \mu \mathrm{m}$. Os cortes foram coloridos com acridina-vermelha, crisoidina e azul-de-astra (Dujardin, 1964), desidratados em série alcoólica ascendente $(30 \%, 50 \%, 75 \%, 90 \%, 95 \%$, duas vezes álcool absoluto) e montados em lâminas permanentes, com Entellan.

Das amostras de madeira, preparou-se, ainda, um quarto corpo-de-prova, com vistas à maceração. Usou-se, neste caso, a técnica de 

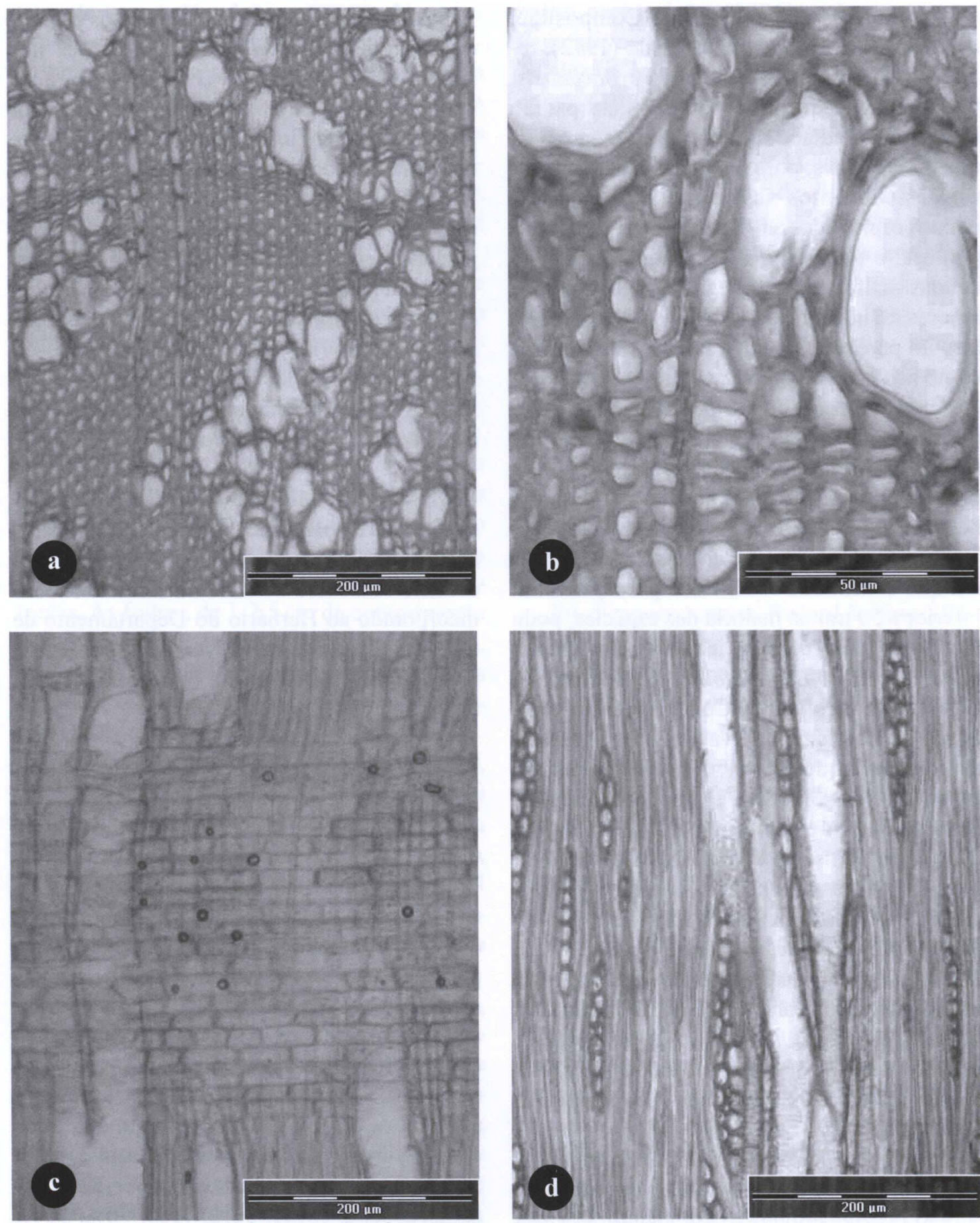

FIGURA 1 - Aspectos anatômicos da madeira de Baccharis dracunculifolia. Anel de crescimento distinto e arranjo dendrítico de vasos, em seção transversal (a). Limite de anel, vasos e parênquima axial, em seção transversal (b). Raio com células procumbentes e fileira marginal de células quadradas, em seção longitudinal radial (c). Raios com 1-3 células de largura, em seção longitudinal tangencial (d). 
Jeffrey (Burger \& Richter, 1991), sendo a pasta resultante tingida com solução aquosa de safranina $1 \%$. A desidratação e montagem de lâminas permanentes seguiram o anteriormente descrito, com a diferença de que a primeira etapa foi desenvolvida sobre papel de filtro.

A descrição microscópica das madeiras baseou-se nas recomendações e terminologia do Iawa Committee (1989).

\section{DESCRIÇÕES ANATÔMICAS}

\section{Baccharis dracunculifolia DC.}

Anéis de crescimento distintos (Figura 1a,b). Porosidade difusa. Vasos de $28 \pm 5 \mu \mathrm{m}$ de diâ- metro, agrupados em múltiplos radiais e racemiformes, compondo um padrão dendrítico (Figura 1a). Elementos vasculares de $202 \pm 26$ $\mu \mathrm{m}$ de comprimento, com espessamentos espiralados na parede e apêndices geralmente em ambas as extremidades; placas de perfuração simples, oblíquas (Figura 2b). Pontoações intervasculares alternas, diminutas a pequenas (4-5 $\mu \mathrm{m})$. Pontoações raio-vasculares com aréolas distintas, semelhantes em tamanho e forma às intervasculares (Figura 2a). Traqueídeos vasculares, tiloses e gomas, ausentes no material em estudo. Parênquima axial paratraqueal confluente, com 2 células por série e células fusiformes freqüentes. Raios com
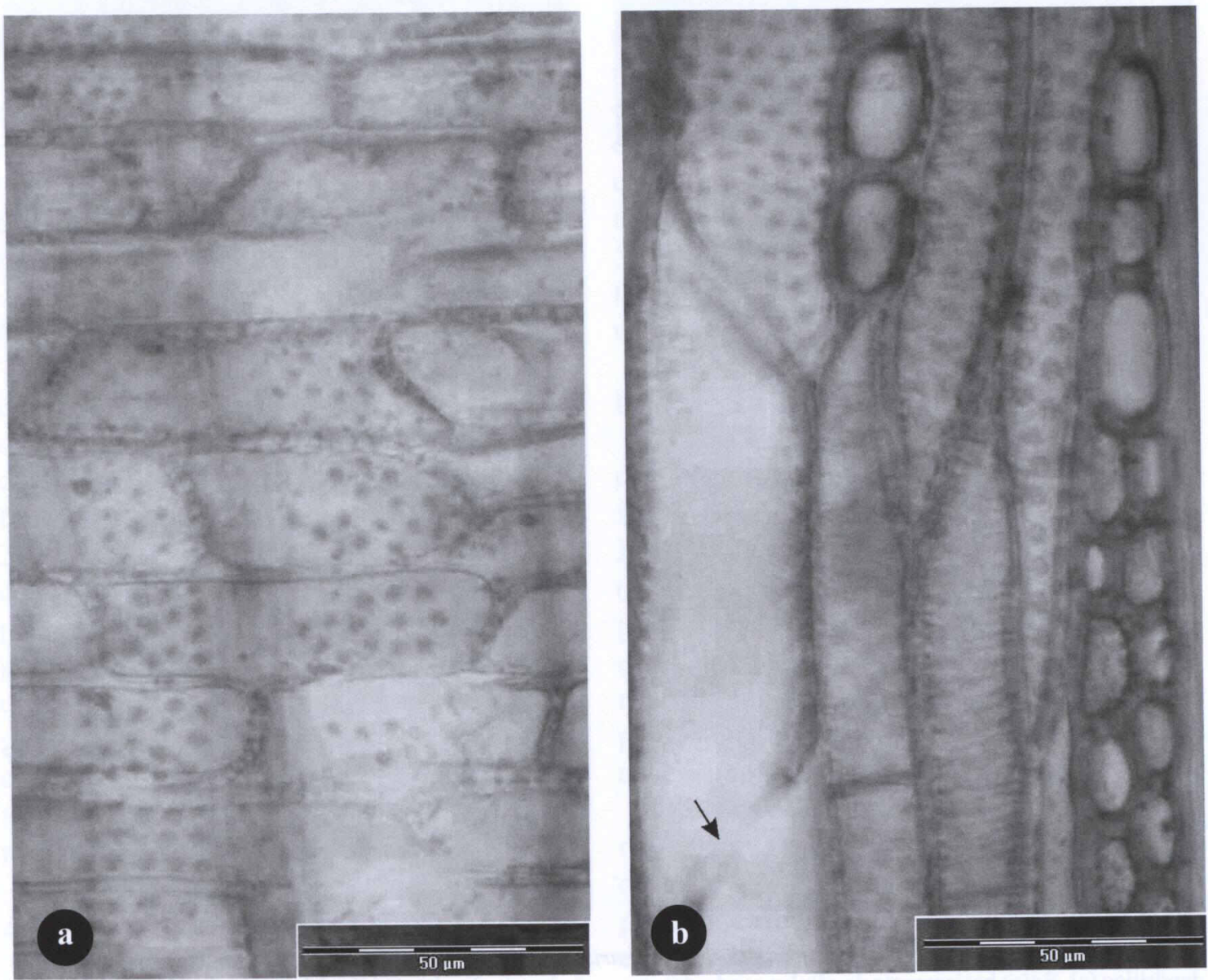

FIGURA 2 - Detalhes anatômicos da madeira de Baccharis dracunculifolia. Células procumbentes e pontoado raiovascular, em seção longitudinal radial (a). Vaso com placa de perfuração simples (seta), raios e séries de parênquima axial, em seção longitudinal tangencial (b). 

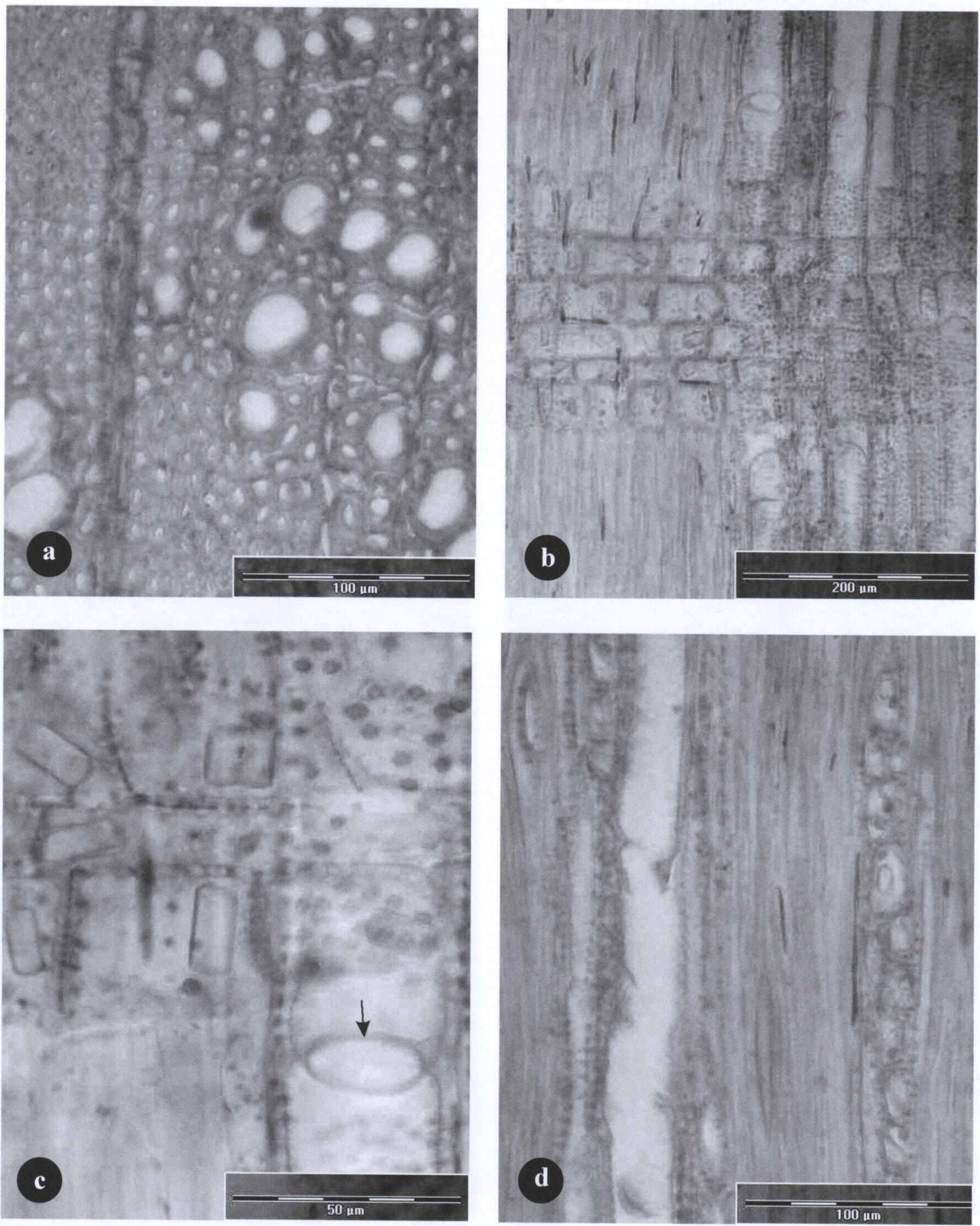

FIGURA 3 - Aspectos anatômicos da madeira de Baccharis patens. Seção transversal, mostrando vasos em padrão dendrítico (a). Raios basicamente de células quadradas, em seção longitudinal radial (b). Mesma seção, destacando placa de perfuração simples (seta) e cristais prismáticos em células radiais (c). Aspecto da seção longitudinal tangencial (d). 
1-3 células de largura (Figura 1d) e $215 \pm 90 \mu \mathrm{m}$ de altura, não estratificados e com freqüência superior a $5 / \mathrm{mm}$; raios compostos de células procumbentes, no centro, e usualmente uma fileira marginal de células quadradas (Figura 1c); cristais aciculares $(6-8 \mu \mathrm{m})$, em pequeno número nas células radiais; células oleíferas, células envolventes, células perfuradas e canais intercelulares, ausentes. Fibras não septadas, de 646 $\pm 96 \mu \mathrm{m}$ de comprimento, com paredes estreitas até espessas e pontoações simples; fibras septadas e espessamentos espiralados, ausentes.

\section{Baccharis patens Baker}

Anéis de crescimento indistintos. Porosidade difusa. Vasos de $25 \pm 5 \mu \mathrm{m}$ de diâmetro, agrupados em múltiplos radiais e racemiformes, compondo um padrão dendrítico (Figura 3a). Elementos vasculares de $143 \pm 17 \mu \mathrm{m}$ de comprimento, com espessamentos espiralados na parede e apêndices geralmente em ambas as extremidades; placas de perfuração simples, oblíquas (Figura 3c). Pontoações intervasculares alternas, diminutas $(<5 \mu \mathrm{m})$; pontoações raiovasculares distintamente areoladas, semelhantes às intervasculares em forma e tamanho. Traqueídeos vasicêntricos, traqueídeos vasculares, tiloses e gomas, ausentes no material em estudo. Parênquima axial paratraqueal escasso, fusiforme ou com 2 células por série. Raios com 1-3 células de largura (Figura 3d) e $200 \pm 101 \mu \mathrm{m}$ de altura, não estratificados e com freqüência superior a $6 / \mathrm{mm}$; raios compostos basicamente de células quadradas (Figura 3b); cristais prismáticos de 15-25 $\mu \mathrm{m}$ de comprimento, abundantes em células radiais (Figura 3c); células oleíferas, células perfuradas e canais intercelulares, ausentes. Fibras não septadas, de $521 \pm 68 \mu \mathrm{m}$ de comprimento, com pontoações simples e paredes muito espessas.

\section{Baccharis tridentata Vahl}

Anéis de crescimento indistintos (Figura $4 \mathrm{a}, \mathrm{b})$. Porosidade difusa. Vasos de $36 \pm 4 \mu \mathrm{m}$ de diâmetro, agrupados comumente em múltiplos radiais e racemiformes de 4 ou mais poros, sem compor, todavia, um nítido padrão dendrítico (Figura 4a,b). Elementos vasculares de $198 \pm$ $19 \mu \mathrm{m}$ de comprimento, com espessamentos espiralados na parede, com placas de perfuração simples, oblíquas (Figura 4c, 5a) e apêndices geralmente em ambas as extremidades. Pontoações intervasculares alternas, diminutas a pequenas $(4-5 \mu \mathrm{m})$; pontoações raio-vasculares com aréolas distintas, semelhantes às intervasculares em tamanho e forma. Traqueídeos vasicêntricos, tiloses e gomas, ausentes no material em estudo. Parênquima axial paratraqueal vasicêntrico-confluente, geralmente com 2 células por série (Figura $5 b$ ); células fusiformes, freqüentes. Raios de $251 \pm 145 \mu \mathrm{m}$ de altura e 2-4 células de largura (Figura 4d), não estratificados, com frequiência superior a $7 /$ $\mathrm{mm}$; raios compostos de células procumbentes, no centro, e uma ou mais fileiras marginais de células quadradas; células oleíferas, células envolventes, células perfuradas e canais intercelulares, ausentes; cristais aciculares, presentes em células radiais. Fibras não septadas, de $572 \pm 67 \mu \mathrm{m}$ de comprimento, com paredes estreitas até espessas e pontoações simples; espessamentos espiralados, ausentes em fibras.

\section{DISCUSSÃO}

Os caracteres anatômicos comuns às três espécies em estudo são de larga ocorrência na família Asteraceae (ou Compositae), segundo Record \& Hess (1949) e Metcalfe \& Chalk (1972): porosidade difusa; poros de diâmetro pequeno, numerosos, com placas de perfuração simples e espessamentos espiralados na parede; pontoações intervasculares alternas; parênquima paratraqueal; e fibras com pontoações simples muito pequenas.

A ocorrência de vasos com diâmetro inferior a $50 \mu \mathrm{m}$, observada no material em estudo e comum à maioria das Astereae (Carlquist, 1960), pode ser atribuída tanto à posição filética mais elevada da tribo, dentro das Compositae, como à especialização acelerada, vinculada à xeromorfia. No caso da interpretação ecológica, a observação do caráter justifica-se facil- 

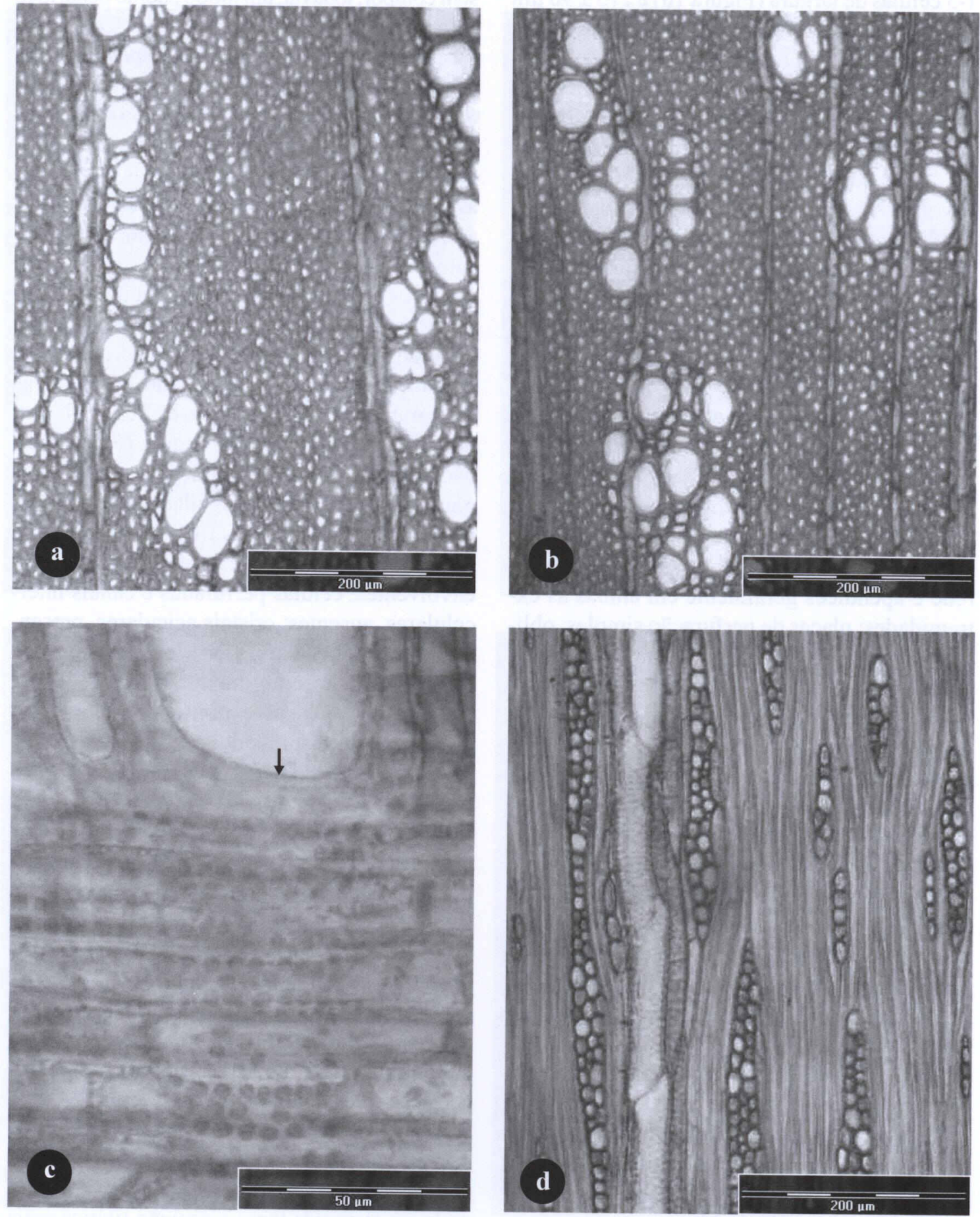

FIGURA 4 - Aspectos anatômicos da madeira de Baccharis tridentata: vasos em múltiplos radiais e racemiformes, em seção transversal $(\mathrm{a}, \mathrm{b})$. Seção longitudinal radial, mostrando placa de perfuração simples (seta) e pontoado raio-vascular (c). Raios não estratificados, com 1-3 células de largura, em seção longitudinal tangencial (d). 

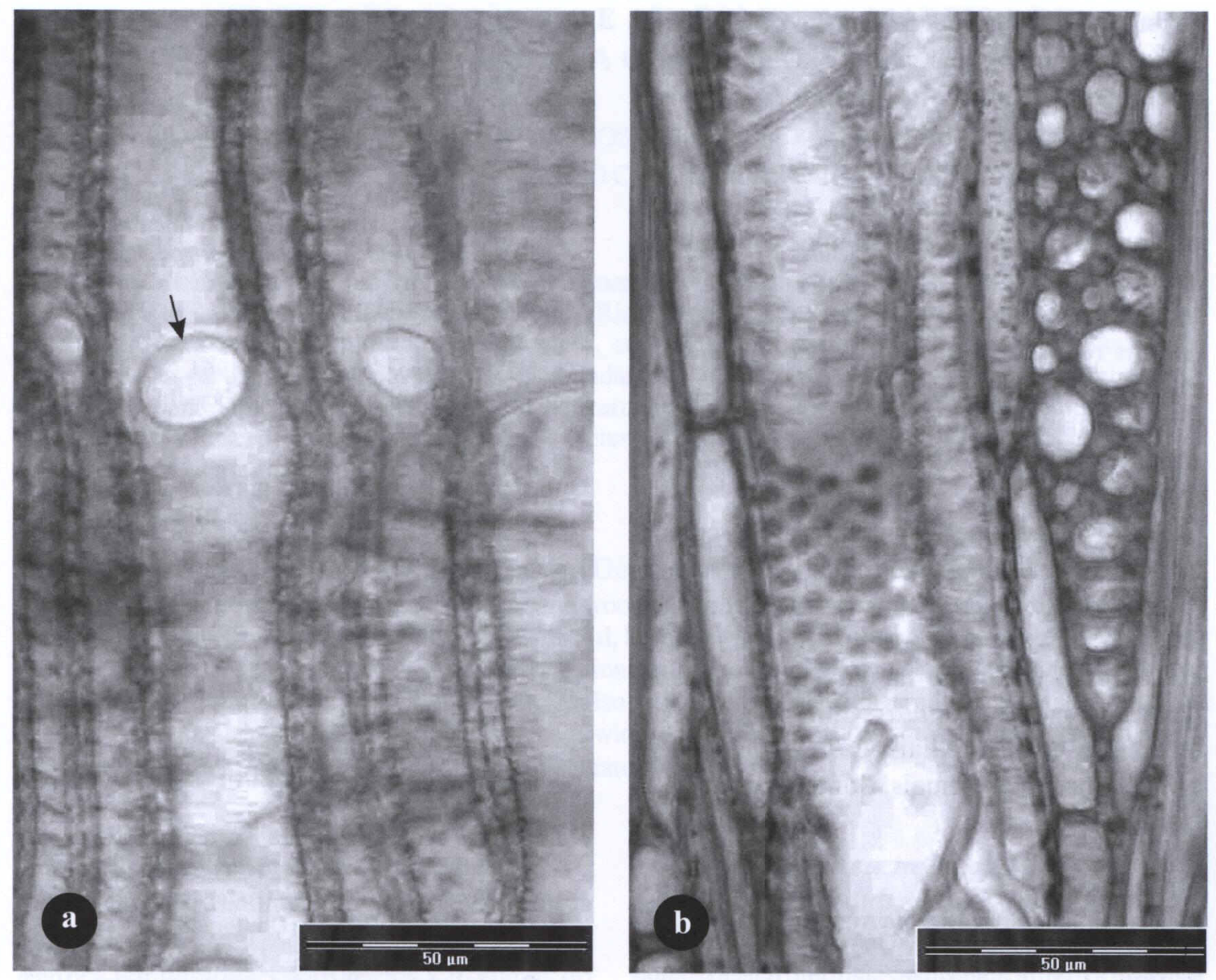

FIGURA 5 - Detalhes anatômicos da madeira de Baccharis tridentata: Vasos com placas de perfuração simples (seta), em seção longitudinal radial (a). Raio trisseriado, pontoado intervascular alterno e parênquima axial com duas células por série, em seção longitudinal tangencial (b).

mente no presente caso, pois as três espécies em estudo são típicos arbustos da flora campestre (vassouras), providos de nítidos caracteres xeromórficos.

A presença de espessamentos espiralados, aspecto muito característico em Baccharis dracunculifolia, B. patens e B. tridentata, segue a mesma estratégia ecológica, proporcionando a vantagem de aumentar a superfície interna dos vasos e, portanto, a sua capilaridade (Carlquist, 1966). De modo análogo, a ocorrência de vasos numerosos e de pequeno diâmetro, traço anatômico comum em espécies xeromórficas, também proporciona maior capilaridade por unidade de volume da madeira; a presença de elementos vasculares curtos $(<250 \mu \mathrm{m})$, por sua vez, traz a vantagem de proporcionar maior número de placas de perfuração por unidade de volume e, por conseguinte, uma maior capilaridade ao xilema secundário, aspecto relevante em espécies xeromórficas (Carlquist, 1966).

Carlquist (1966) também chama atenção para o fato de que o hábito arbóreo geralmente indica mesomorfia em Compositae. Deste modo, a conhecida tendência a vasos agregados e de menor diâmetro em arbustos - caso típico das três espécies em estudo -, pode facilmente ser 
atribuída ao hábito vegetal, posto que espécies arbustivas predominam em locais mais secos, diferentemente do hábito arbóreo.

Ao contrário da maioria das Compositae (Record \& Hess, 1949), as espécies aqui descritas não apresentam fibras septadas; suas pontoações, todavia, são simples e pequenas, como de regra na família. Com relação à presença de cristais prismáticos e aciculares em células radiais de Baccharis dracunculifolia e $B$. patens, cabe salientar que o caráter, embora raro na família (Metcalfe \& Chalk, 1972), permite segregar estas duas espécies de $B$. tridentata.

Para a identificação anatômica, resta comentar sobre a visibilidade dos anéis de crescimento e a natureza das células radiais. Com seus anéis de crescimento distintos, Baccharis dracunculifolia separa-se facilmente de Baccharis patens e $B$. tridentata. Com relação à natureza das células radiais, é Baccharis patens que separa-se das demais, por ter apenas células quadradas.

\section{BIBLIOGRAFIA}

Barroso, G. M. Sistemática de Angiospermas do Brasil. Viçosa: Editora UFV, 1991. v. 3. 326 p.

Barroso, G. M. Compositae, subtribo Baccharidinae Hoffman. Estudo das espécies ocorrentes no Brasil. Rodriguésia, Rio de Janeiro, v. 28, p. 3-273. 1976.

Bonzani-da-Silva, J., Grotta, A. S. Anatomy of the leave and essential oil of Baccharis retusa DC. (Compositae). Rev. Farm. Bioq. Univ. São Paulo, v. 9, n. 2, p. 321-326, 1971.

Bremer, K. Asteraceae - cladistics \& classification. Portland: Timber Press, 1994. 728 p.

Budel, J. M., Duarte, M. R., Santos, C. A. M. Caracteres morfo-anatômicos de Baccharis gaudichaudiana DC., Asteraceae. Acta Farm. Bonaerense, v. 22, n. 4, p. 313-320, 2003.

Budel, J. M., Duarte, M. R., Santos, C. A. M. Stem morpho-anatomy of Baccharis cylindrica (Less.) DC., Asteraceae. Revista Brasileira de Ciências Farmacêuticas, v. 40, n. 1, p. 93-99, 2004a.

Budel, J. M., Duarte, M. R., Santos, C. A. M., Farago, P. V. Morfoanatomia foliar e caulinar de Baccharis dracunculifolia DC., Asteraceae. Acta Farm. Bonaerense, v. 23, n. 4, p. 477-483, 2004b.

Burger, L. M., Richter, H. G. Anatomia da madeira. São Paulo: Ed. Nobel, 1991. 154 p.

Carlquist, S. Wood anatomy of Astereae (Compositae). Tropical Woods, n. 113, p. 54-84, 1960.
Carlquist, S. Wood anatomy of Compositae: a summary, with comments on factors controlling wood evolution. Aliso, v. 6, n. 2, p. 25-44, 1966.

Castro, H. G., Ferreira, A. F. Contribuição ao estudo das plantas medicinais: carqueja (Baccharis genistelloides). Viçosa: UFV, 2000. 102 p.

Cortadi, A., Sapio, O., Mc-Cargo, J., Scandizzi, A., Gattuso, S., Gattuso, M. Anatomical studies of Baccharis articulata, Baccharis crispa and Baccharis trimera, "carquejas" used in folk medicine. Pharmaceutical Biology, v. 37, n. 5, p. 357-365, 1999.

Dujardin, E. P. Eine neue holz-zellulozenfaerbung. Mikrokosmos, n. 53, p. 94, 1964.

Giuliano, D. A. Subtribo Baccharidinae. In: Hunziker, A. T. Flora Fanerogámica Argentina. Córdoba, 2000. v. $66.73 \mathrm{p}$.

Iawa Committee. Iawa list of microscopic features for hardwood identification. Iawa Bulletin, v. 10, n. 3, p. 218-359, 1989.

Jakupovic, J., Schuster, A., Ganzer, U., Bohlmann, F., Boldt, P. E. Sesqui and diterpenes from Baccharis species. Phytochemistry, v. 29, n. 7, p. 2217-2222, 1990.

Loyaza, I., Abujder, D., Aranda, R., Jakupovic, J., Collin, G., Deslauriers, H., Jean, F. I. Essential oils of Baccharis salicifolia, $B$. latifolia and $B$. dracunculifolia. Phytochemistry, v. 38, n. 2, p. 381$389,1995$.

Marinho, T, C. Anatomia e ultra-estrutura dos órgãos vegetativos de Baccharis pseudotenuifolia Teodoro e B. dracunculifolia DC. (Asteraceae). São Paulo: USP, 1966. $101 \mathrm{f}$. Tese (Doutorado).

Metcalfe, C. R., Chalk, L. Anatomy of the Dicotyledons. Oxford: Clarendon Press, 1972. $1500 \mathrm{p}$.

Neson, G. L. Generic conspectus of the tribe Astereae (Asteraceae) in North America, Central America, the Antilles and Hawaii. Sida Botanical Miscellany, Fort Worth, n. 20, p. 1-100, 2000.

Oliveira, A. S. de, Deble, L. P., Schneider, A. A., Marchiori, J. N. C. Checklist do gênero Baccharis L. para o Brasil (Asteraceae-Astereae). Balduinia, n. 9, p. 17-27, 2006.

Pereira, L. T., Oliveira, P. L. de. Anatomia do caule de Baccharis cylindrica (Less.) DC. (Asteraceae). Comun. Mus. Ciênc. Tecnol. PUCRS, Série Botânica, v. 2, n. 1, p. 29-48, 1996.

Record, S. J., Hess, R. W. Timbers of the New World. New Haven: Yale University Press, 1949. 640 p.

Suttisri, R., Kinghorn, A. D., Wright, A. D., Sticher, O. Neo-clerodane diterpenoids and other constituents from Baccharis genistelloides. Phytochemistry, v. 35, n. 2, p. 443-446, 1994.

Verdi, L. G., Brighente, I. M. C., Pizzolatti, M. G. Gênero Baccharis (Asteraceae): aspectos químicos, econômicos e biológicos. Quím. Nova, v. 28, n. 1, p. 8594, 2005. 